\title{
MICRO DSC AND NMR MOUSE STUDIES OF COLLAGEN-VEGETABLE TANNIN INTERACTION MECHANISM DURING LEATHER MAKING
}

\author{
CLAUDIU ȘENDREA ${ }^{1}$, MARIA-CRISTINA MICU ${ }^{1}$, EMANUEL HADIMBU ${ }^{1}$, SIMONA \\ MARIA PĂUNESCU ${ }^{1}$, IULIA MARIA CANIOLA ${ }^{1}$, MADALINA IGNAT ${ }^{1}$, LUCRETIA MIU ${ }^{1}$, \\ ELENA BADEA ${ }^{1,2^{*}}$ \\ ${ }^{1}$ INCDTP - Leather and Footwear Research Institute (ICPI) Division, Bucharest, Romania, \\ elena.badea@unito.it \\ ${ }^{2}$ Department of Chemistry, Faculty of Sciences, University of Craiova, Craiova, Romania
}

\begin{abstract}
In this study NMR MOUSE and micro DSC techniques were used to investigate the interaction between collagen and various vegetable tannins during leather making process with the aim of gaining a deeper understanding of different water environment in relation to tannin type. We have previously showed that relaxation times may provide useful information on collagen matrix properties. The vegetable tanned leathers were obtained by patented techniques inspired from ancient recipes at the National R\&D Institute for Textile and Leather, ICPI Division, Bucharest using various vegetable extracts such as myrobalan, gambier and chestnut. Longitudinal and transversal relaxation times $T_{1}$ and $T_{2 \text { eff }}$ were measured using a PM2 portable NMR-MOUSE with 20.05 MHz frequency. Micro DSC measurements were carried out with a high-sensitivity SETARAM Micro-DSC III in the temperature range (5 to 95$){ }^{\circ} \mathrm{C}$ at $0.5 \mathrm{~K} \mathrm{~min}^{-1}$ heating rate. The investigated leathers showed significant differences in the values of spin-spin $\left(T_{2 \mathrm{eff}}\right)$ and spinlattice $\left(T_{1}\right)$ relaxation times depending on tannin type that well corelates with the variation of the calorimetric parameters (denaturation temperature and enthalpy, peak shape). These results highlight the complementarity of the information obtained by the two techniques and open new ways for both designing new leather assortments and analyses of historical and archaeologica leather.
\end{abstract}

Keywords: unilateral NMR, micro DSC, vegetable tanned leather, collagen-tannin interaction

\section{INTRODUCTION}

Since ancient times people have been soaking the skins in natural tannins to dehydrate them and prevent the leather goes stiff and putrescible. The vegetable tannin solutions were made up of organic substance present in trees (such as oak, chestnut or mimosa), or a large number of other types of plants. Starting from the second half of the XIX century chrome tanning became the most common and dominant form of tanning. Chrome tanning brought about a number of innovation in tanning such as a fat liquoring (re-greasing) process and the use of synthetic dyes. Besides, the process was much faster than vegetable tanning. Today, more than $90 \%$ of leather production is based on chrome tanning. However, the leather industry is facing a number of challenges including a continuously tightening regulatory framework for safer and cleaner chemicals and technologies and the ongoing need to differentiate in terms of innovativeness, design, appearance and comfort. So far, vegetable tanning has returned in the leather industry focus, although it requires a high degree of craftmanship.

This paper concerns with the tanning reaction and the origin of hydrothermal stability in vegetable tanned leather. Micro differential scanning calorimetry (micro DSC) was used to quantify the increase in hydrothermal stability upon tanning with various vegetable extracts such as gambier, myrobalan and chestnut. The transverse relaxation time $T_{2}$ measured by Unilateral Nuclear Magnetic Resonance (NMR MOUSE) provided information related to the dynamics of water molecules inside the collagen matrix, while the longitudinal relaxation time $T_{1}$ was related to the collagentannin matrix strength.

https://doi.org/10.24264/icams-2020.V.13 


\section{MATERIALS AND METHODS}

\section{Tannins and Vegetable Tanned Leather}

The vegetable extracts were from Seta S.A., Brazil and Silva Team S.P.A., Italy. Goat hides were tanned using a patented technology inspired from ancient recipes (Miu et al., 2006).

\section{Micro Differential Scanning Calorimetry (Micro DSC) Measurement}

The measurement of hydrothermal stability of pelt and the derived vegetable tanned hides was carried out with a high-sensivity microDSC III Setaram microcalorimeter equipped with Haake DC10 circulator for stabilizing the heating/cooling temperature. Samples were hydrated in $0.5 \mathrm{M}$ acetate buffer solution with $\mathrm{pH} 5.0$ for $1 \mathrm{~h}$, directly in the calorimetric cells, and then heated in the temperature range $(25$ to 95$){ }^{\circ} \mathrm{C}$ at 0.5 $\mathrm{K} \cdot \mathrm{min}^{-1}$ heating rate as previously reported (Carsote and Badea, 2019; Carşote et al., 2016). Three measurements were run using fresh subsamples. Experimental DSC data acquired with the SETARAM SetSoft2000 software were analysed using PeakFit 4.1 (Jandel Scientific) software. Denaturation temperature, $T_{\max }$, was determined as the temperature attained at peak maximum. Temperature span of the transition was reported as peak width at half height, $\Delta T_{1 / 2}$, and specific denaturation enthalpy, $\Delta H$ was calculated as the area under the peak by integrating $C_{p}^{e x}(T)$ curve across the denaturation temperature range.

\section{Unilateral Magnetic Resonance (NMR MOUSE) Measurement}

${ }^{1} \mathrm{H}$ NMR measurements were performed at room temperature using an NMR MOUSE PM2 (Magritek GmbH) controlled by a Kea 2 spectrometer (Magritek GmbH) operating at $27 \mathrm{MHz}{ }^{1} \mathrm{H}$ resonance frequency as described earlier (Badea et al., 2016; Sendrea et al., 2016). This system allows to measure proton relaxation times without any previous preparation of the samples. Effective ${ }^{1} \mathrm{H}$ spin-spin relaxation $T_{2 \mathrm{eff}}$ measurements have been measured using the Carr-Purcell-Meiboom-Gill (CPMG) pulse sequence with an echo-time (TE) of about $25 \mu$ s. The experimental CPMG curves were best analyzed by a combination of double exponential functions. The proton spin-lattice relaxation times $T_{1}$ were measured with a saturation-recovery pulse sequence using a Hahn-echo with an echo time of about $25 \mu$ for detection. The analysis of the saturation recovery data was best performed with the help of a single exponential function.

\section{RESULTS AND DISCUSSION}

\section{Effect on Tannin Type on Leather Hydrothermal Stability}

The micro DSC denaturation curves for the vegetable tanned leathers are shown in Figure 1 together with the DSC curve for pelt (not tanned hide) as comparison. The calorimetric parameters that characterize the collagen matrix denaturation in vegetable tanned leathers, chrome-tanned leather and pelt are listed in Table 1. Hydrolysable (myrobalan and chestnut) tanned leathers show similar denaturation curves and parameters, while the condensed (gambier) tanned leather shows higher $T_{\text {onset }}$ and $T_{\max }$ 
and lower $\Delta T_{1 / 2}$, as expected: thermal stability and structural homogeneity increase as tanning efficiency increases.

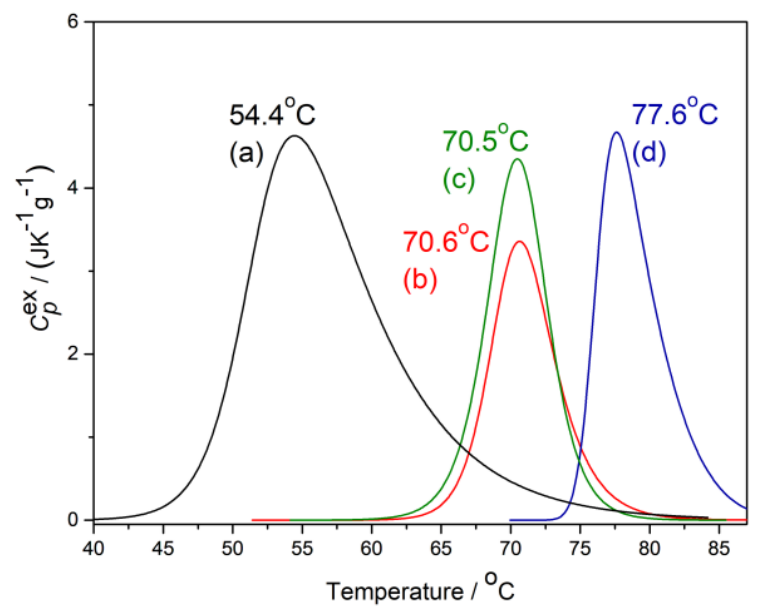

Figure 1. DSC denaturation peaks for vegetable tanned leathers $(b-$ myrobalan, $c-$ chestnut, $d$-gambier) compared to those of pelt (a)

Table 1. DSC parameters of thermal denaturation of vegetable tanned leathers compared to pelt and chrome tanned leather

\begin{tabular}{|c|c|c|c|c|}
\hline Samples & $\Delta H / \mathrm{J} \cdot \mathrm{g}^{-1}$ & $T_{\text {onset }} /{ }^{\circ} \mathrm{C}$ & $T_{\max } /{ }^{\circ} \mathrm{C}$ & $\Delta T_{1 / 2} /{ }^{\circ} \mathrm{C}$ \\
\hline Leather - gambier & 28 & 74.6 & 77.6 & 4.8 \\
\hline Leather - myrobalan & 26 & 65.9 & 70.6 & 5.3 \\
\hline Leather - chestnut & 33 & 65.8 & 70.5 & 5.0 \\
\hline Leather- chrome ${ }^{1}$ & $50-54$ & - & 111.2 & 3.5 \\
\hline Pelt & 56 & 47.3 & 54.5 & 10.4 \\
\hline
\end{tabular}

${ }^{1}$ Values reported by Cucos et al. (2015)

\section{Effect on Tannin Type on Transverse Relaxometric Parameters}

The values of $T_{1}, T_{2 \text { eff_short }}$ and $T_{2 \text { eff_long }}$ are shown in Table 2 . It is noteworthy that $T_{1}$ values increased in the following order: chrome-tanned leather < gambier (catechin) tanned leather < myrobalan (ellagitannin) tanned leather < chestnut (ellagitannin) tanned leather < pelt (not tanned collagen). This behaviour indicates that the collagentannin interaction causes a variation of $T_{1}$ values, and the extent to which $T_{1}$ varies depends on the chemical nature of the tannin. Some of us have already reported that $T_{1}$ values allowed to differentiate between the effects of hydrolysable and condensed tannins on collagen water environment in calf leathers (Badea et al., 2016). By comparing the values of the proton longitudinal relaxation times $T_{1}$ with those of the corresponding temperature of denaturation $T_{\max }$ an inverse correlation is observed: the highest value of $T_{1}$ corresponds to the least thermally stable collagenous material, i.e. pelt (not tanned collagen). 
Table 2. $T_{1}$ and $T_{2 \text { eff }}$ relaxation time values for vegetable tanned leathers compared to chrome tanned leather and parchment (not tanned collagen)

\begin{tabular}{lccc}
\hline Samples & $T_{1} / \mathrm{ms}$ & $T_{\text {2eff_long }} / \mathrm{ms}$ & $T_{\text {2eff_short }} / \mathrm{ms}$ \\
\hline Leather - chestnut & 42.1 & 4.66 & 0.31 \\
Leather - myrobalan & 40.1 & 4.18 & 0.26 \\
Leather - gambier & 36.4 & 2.65 & 0.24 \\
Leather - chrome & 9.6 & 1.29 & 0.13 \\
Parchment & 50.3 & 0.93 & 0.16 \\
\hline
\end{tabular}

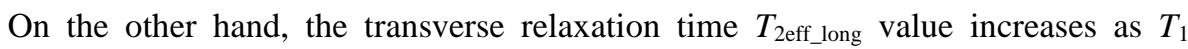
increases for leather while the relaxometric behaviour of parchment is different - it presents the lowest value $T_{2 \text { eff_long }}$ and the highest $T_{1}$ value. We will explain this behaviour by considering that the two $T_{2}$ components correspond to water in various environments. In fact, Rodin et al. (2000) reported that different degree of cross linking in collagen fibres affects the water dynamics. This was directly related to the fibrous collagen microstructure and chain mobilities in the collagen matrix, namely $T_{2 \text { eff_short }}$ relates to the crystalline phase and $T_{2 \text { eff_long }}$ to the amorphous phase (Nishad Fathima $e t$ al., 2010; Sendrea et al., 2017). The increase of chain mobility in vegetable tanned leather by comparison with parchment and chrome-tanned leather could thus be interpreted in terms of a looser packing of collagen fibrils in both the amorphous and crystalline phases. This is in good agreement with the lower hydrothermal stability of vegetable tanned leather by comparison with chrome tanned leather. In case of parchment, the strong dehydration during drying under tension results in a tighter packing of collagen fibrils and restricted chain mobility. It is worthy of note that the second water fraction $T_{\text {2eff_long, }}$ being much more mobile, feels better the influence of the tanning agents. Our results confirm the previous data obtained on sheep leather: $T_{2 \text { eff_long }}$ values discriminate between condensed and hydrolysable tannins (Badea et al., 2016).

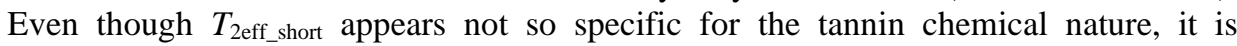
sensitive to the chain mobility constraints, being discriminative for chemically bound and chemically unbound collagen as already reported by some of us (Badea et al., 2016).

\section{CONCLUSIONS}

In the present work unilateral NMR and micro DSC were used to discriminate between the tanning chemistry of hydrolysable and condensed tannins. The effect of collagen-tannin interaction was discusses based on water dynamics in collagenous matrices and their hydrothermal stability. The main conclusions may be summarized as follows:

- $\quad T_{2 \text { eff_long }}$ and $T_{1}$ relaxation values are discriminative for the chemical nature of tannin;

- $\quad T_{2 \text { eff_short }}$ is discriminative between chemically bound (tanned) and unbound (not tanned) collagen;

- $\quad$ an inverse correlation is observed between $T_{\max }$ and $T_{1}$ values;

- $\quad$ the relaxometric parameters confirms a looser packing of collagen fibrils in both the amorphous and crystalline phase in vegetable tanned leather compared to chrome tanned leather. 
Micro DSC and unilateral NMR are complementary techniques that sensitively discriminate for the nature of collagen-tannin interaction and may thus be successfully applied to validate new chrome-free tanning technologies, as well as to characterize historical and archaeological leather.

\section{Acknowledgement}

This work was supported by a grant of the Romanian Ministry of Research and Innovation (now Ministry of Education and Research), CCCDI - UEFISCDI, project number PN-III-P1- 1.2-PCCDI-2017-0878/ no. 55PCCDI/2018, IMPLEMENT.

\section{REFERENCES}

Badea, E., Şendrea, C., Carşote, C., Adams, A., Blümich, B. and Iovu, H. (2016), "Unilateral NMR and thermal microscopy studies of vegetable tanned leather exposed to dehydrothermal treatment and light irradiation", Microchem. J., 129, 158-165, https://doi.org/10.1016/j.microc.2016.06.013.

Carsote, C. and Badea, E. (2019), "Micro differential scanning calorimetry and micro hot table method for quantifying deterioration of historical leather", Herit Sci, 7, 48, https://doi.org/10.1186/s40494-019-0292-8.

Carşote, C., Badea, E., Miu, L. and Della Gatta, G. (2016), "Study of the effect of tannins and animal species on the thermal stability of vegetable leather by differential scanning calorimetry", J. Thermal. Anal. Calorim., 124(3), 1255-1266, https://doi.org/10.1007/s10973-016-5344-7.

Cucos, A., Gaidau, C., Badea, E. and Miu, L. (2015), "Influence of glycerin on denaturation temperature of chrome- and vegetable-tanned leather", Rev. Roum. Chim., 60(11-12), 1093-1096.

Miu, L., Bratulescu, V., Gaidau, C., Bocu, V. and Niculescu O. (2006), Natural leather for bookbinding for heritage and process of making thereof (in Romanian), Romanian patent C14C/2006, available at p.31 at http://www.osim.ro/publicatii/brevete/bopi_2006/bopi0306.pdf.

Nishad Fathima, N., Baias, M., Bluemich, B. and Ramasami, T. (2010), "Structure and dynamics of water in native and tanned collagen fibers: Effect of crosslinking", Int J Biol Macromol, 47, 590-596, https://doi.org/10.1016/j.ijbiomac.2010.08.003.

Rodin, V.V., Sakharov, B.V. and Knight, D.P. (2000), "Hydrated polymer matrices: NMR-relaxation and PFG-NMR in study of molecular mobility", Plast. Massy, 2, 13-24.

Sendrea, C., Badea E. and Adams, A. (2017), "Unilateral NMR and micro DSC study of artificially aged parchments", Rev. Chim., 68(8), 1780-1785, https://doi.org/10.37358/RC.17.8.5764.

Sendrea, C., Carsote, C., Badea, E., Adams, A., Niculescu, M. and Iovu, H. (2016), "Non-invasive characterisation of collagen-based materials by NMR-MOUSE and ATR-FTIR", U.P.B. Sci. Bull., Series Chemistry, 78(3), 27-38. 
Micro DSC and NMR MOUSE Studies of Collagen-Vegetable Tannin Interaction Mechanism During Leather Making

https://doi.org/10.24264/icams-2020.V.13 